\title{
THE IMPLEMENTATION OF COLLABORATIVE STRATEGY WITH INTEGRATED WRITING SKILLS IN ENGLISH LANGUAGE CLASSROOM AT MERCUBUANA UNIVERSITY
}

\author{
Budiarto, M.Hum \\ Lecturer of STIBA-IEC Jakarta \\ budiart2003@yahoo.com
}

\begin{abstract}
The purpose of this study is to investigate on how the teaching of integrated writing skills can be implemented through collaborative strategy. Writing skills need to be combined with other skills, because students need a lot of reading in order to obtain information, ideas and examples of correct writing. On the other hand feedback and ideas can also be gained by listening to what the teacher or a friend says. Fellow students can also discuss their writing and work together to develop ideas, discuss the use of grammar, the right words and rules in writing. Since writing skills requires a lot of rules and a long process, the collaboration is expected to reduce the burden experienced by the students. However, teachers should ensure that the collaboration is actually done by students properly by observing their activity, participation, and motivation in writing. Peer-reviewing activities can be used to monitor on how students actively engage in the writing process. Research was conducted at Mercubuana University is a qualitative research that focuses on how a lecturer teaches the students writing skills as an integrated skill, how she facilitates students to actively participate in collaborative writing, and how effectively she encourages the students to do peer reviewing.
\end{abstract}

Keywords: integrated writing skills, collaborative strategy, peer reviewing

\section{A. INTRODUCTION}

\section{Background}

Collaborative writing allows students to help one another despite differences of background knowledge. The collaboration will be successful if the members involved have the same purpose. When they know their purpose, they will be motivated because they are sure what they have to do. Collaboration works well not only when it is aimed to solve problems of academic writing in the short term goal, but also in the long term goal. As cooperation becomes stronger as time progresses, the long term goal should be emphasized in order 
to develop students' unique writing habits. When writing is done collaboratively in group, indeed other skills such as reading, listening, and speaking directly and indirectly involved. The integration of writing with other skills does not have a definite pattern, yet writing combined with any patterns as long as designed proportionally could foster collaborative writing activity and participation in a group.

For example, when the teacher calls the students to come to the front of the class to write a letter of invitation, another may write to answer the letter of invitation beside him or her. It is interesting to note that their movement in front of the white board could be a stimulus for other students who have a kinesthetic learning style, as their interest is triggered while looking at their friends moving their hands during writing process. On the other hand, students who are sitting in their chairs can be helped visually by observing and analyzing the texts on the board. They need to give each other advice verbally, accept or respond to feedback, and criticize each other so that the learning condition motivate them to interact and think critically. ${ }^{1}$

\section{The Objective}

The objective of this research is to find the process how to implement the Collaborative Strategy for Integrated Writing Skills In English Language Classroom.

\section{Theoretical Framework}

Occasionally, teaching collaborative writing can also be done with the emphasis on the accurate use of grammar and vocabulary. Scott Thornbury suggested the use dictogloss, in which students try to write back what has been told by the teacher. In this exercise, students were asked to focus their attention on the part of grammar and vocabulary covered in the lessons. The students had to listen carefully in order to remember the expressions by writing on a

\footnotetext{
${ }^{1}$ Harmer, Jeremy, How to Teach Writing (Essex: Pearson Education Limited, 2004)
} 
sheet of paper. This exercise is mainly to encourage the habit of writing in addition to helping the acquisition of vocabulary and the correct use of grammar by way of listening and writing. To help students write more accurately, the teacher may use facial expressions and gestures so that the students understand what the teacher told and write it as proof of their comprehension. When finished listening and writing what they heard, students may work in pairs to discuss the results of their writing. At this stage students focus on the big picture of the story, rather than the details. Next, they listen to more stories from teachers to pay more attention to the important fact in the story and grammar used. Then, for the third time and with the same story, the teacher reads aloud again while the students are listening. This time the students are encouraged to write more of his writings and discuss the results with their friends and compare facts or details. The group that has completed the whole story with important facts is asked to attach their discussion paper on the board, so that the results can be compared to the whole class. ${ }^{2}$

Students may focus more on accurate writing when the teacher dictates sentence by sentence. Teachers reads the sentence by sentence loudly and slowly to ensure that no words will be missed. Repetition of reading the passage loudly by teacher is necessary as long as it is not too excessive. By the time the students have finished listening to the dictation of the teacher, they check the punctuation, grammar and spelling to see whether they need to be repaired or not. Eventually, they compare their results with the teacher's version that is displayed on the board.

Instead of listening to a long passage to write, a pair of sentences can be more attractive, in which one is a sentence that gives special characteristics to the male students and the sentence is typical characteristics of a female. For example:

Boys like football. Girls like shopping.

${ }^{2}$ Ibid., p. 74-75 
After writing a pair of sentences on the board, the teacher asks the students to form groups and develop each sentence into one or two paragraphs. The topic can stimulate students to get more ideas through writing because men and women have unique features to be discussed. The two contradictory characteristics create livelier atmosphere. To create such condition, the teacher has to be creative to in order to produce sentences which lead to a heated discussion among the students. Even when the source of discussion is only one sentence, the teacher should make it unique but it is still related to men and women; for example:

The woman saw the man.

A short sentence can actually create a variety of interpretations for these young students. The teacher may ask the students to discuss the short sentence in groups to brain storm ideas. The students may select important information, and they are asked to develop the sentence into a paragraph or story.

As long as the teacher can use interesting resources, students may enjoy the activities. For example, the teacher may use incomplete story which raises students' curiosity. The teacher writes on the blackboard the beginning of interesting or unique story. After the students are asked to copy the beginning of the story, they have to complete the story in group. The practice can be done vice versa; the teacher writes the ending of the story on the board, then the students develop the beginning and the contents of the story. Completing a story can be carried out by several groups, so that when a group is not able to develop the idea in the story, it could be handed over to another group to work with. The results of the overall story usually has a lot of mistakes both in the techniques of writing and grammar. But this kind of practice is not to focus on the accuracy, but on developing ideas through collaborative writing. This exercise is also intended to make students stay active and participate in writing.

Other activities that trigger students to work in group is the use of jigsaw technique. This technique is to make students share ideas using information they have. For example, there are four images $(A, B, C$, and $D)$ to 
be seen at a glance and remembered as the idea of writing a paragraph. So here are four members in one group, and each member must remember the selected image and develop it into a paragraph. When each of them has completed a short paragraph, all four paragraphs are discussed, and they make a complete story based on series of events that occurred. Of course, this may trigger a heated debate, criticism, before they agree on the inputs and create the whole story. The story constructed as a result of contributing members can be submitted to the teacher for review. The group that has the best or the most appropriate story and has the fewest errors of grammar is considered as the winner. ${ }^{3}$

Research conducted by Fong (2012) discusses the collaborative writing in business studies diploma program. To ensure that students can collaborate effectively, they must have a consensus within the group and sign a contract to reinforce the agreement in the group that has been formed.

The activities of the students were recorded with a video camera. They were required to write a brief report on their activities in the classroom. To get reliable data, they were interviewed when the study program ended, so that the researcher can obtain more information on their experience and habits.

Findings from the research shows that the benefits of collaborative writing is to foster a sense of responsibility, new information and skills sharing. Meanwhile, if the activities cannot be solved in the classroom, the students tried to continue the group discussion through Facebook so that they can sort them out. $^{4}$

While the research conducted by Dang (2016) states that theoretically and empirically feedback from members of the group are beneficial because feedback can help achieve learning outcomes. However, finding data on feedback is sometimes tricky to handle due to different viewpoints from the

\footnotetext{
${ }^{3}$ Ibid., p. 76-80

${ }^{4}$ Fong, Lin Siew, Benefits of Collaborative Writing for ESL Advanced Diploma Students in the Production of Reports. Jurnal US-China Education Review, 2012
} 
students. This happens especially because students are searching for the best way to give feedback.

For these reasons, Dang explores perceptions of students about the feedback through the output in the form of writing. Feedback with good quality may reflect student's attention and participation in collaborative learning. Other findings indicate that students feel they get benefits when teachers provide a variety of interesting materials presented through scaffolding techniques before they write in groups. ${ }^{5}$

\section{Methodology}

The research methodology used a qualitative descriptive method as theoretical approaches. The data were collected through observation and document study.

\section{B. RESULT AND DISCUSSION}

While in the case of research conducted at Mercubuana, collaboration will be more challenging when the lecturer directs the students to use English as much as possible during the discussion. However, when the students find difficulty to express their ideas in English they may mix some with Indonesian language. On the one hand, students need to continue to use the target language, but on the other hand Indonesian language can reduce students' anxiety. Code switching is not the goal that should be achieved; it is parts of process that should keep students expressing ideas and interact in the classroom. Thus writing activities are not only limited to integrate with reading alone; expressions or ideas from members of the group can develop their writing. Therefore, speaking skills can be intensified when writing collaboratively implemented.

\footnotetext{
${ }^{5}$ Dang, Trang Thi Doan, Vietnamese EFL Students' Perceptions of Noticing-Based Collaborative Feedback on Their Writing Performance. Jurnal English Language Teaching; Canadian Center of Science and Education, Vol. 9, No. 5; 2016
} 
Research conducted at the University of Mercubuana suggests that the teacher tries to keep the groups without changing the members. However, students are given the freedom to choose their members and given the right to move to another group only when they do not feel comfortable with the people in a group. The students are urged to work together and support each other and do not change the group formation, but when the collaboration is not possible to develop, students may change formation. Although they are not asked to sign an agreement to maintain their collaboration, they are motivated and facilitated by the teacher. The teacher always reminds the students that through collaboration, the burden of doing tasks can be reduced, because each member contribute to accomplish their tasks.

The study conducted at Mercubuana focuses on how the lecturer implements teaching integrated writing through collaborative strategy. The English class observed consists of 14 sessions, with 150 minutes allocated per session or meeting. For each session, students have to write in groups for about an hour. While at the end of each session, students are always assigned to do homework to help them develop their writing in the next session. As writing is an integrated skill, which can be accompanied by other skills such as listening, reading, speaking, the lecturer must be able to facilitate students in such a way that other skills generate students to be more active and productive in their writing. Reading give students ideas or information to develop writing. Some parts of the text can be highlighted or analyzed. Reading passages may give good examples on how writing should be organized. During the writing process, students need input or advice from other students, so they can talk about their writing and listen to others in order to improve their writing. As long as not too much, elements of grammar and vocabulary can help them develop the accuracy in writing. This is especially done as additional activity because grammar and vocabulary practices are not the main focus of the classroom activities. Students' team work will be stronger when each member contribute their work; everybody in the group wants to learn seriously so that the can use their skills and ideas to maximize their work. Collaborative writing can be done at the beginning, in the middle, or at the end of session. However, the activities 
must make students feel comfortable and should be relevant with the material from the book to make them sure what they are doing. In this case, the lecturer is responsible for providing the book or materials that support collaborative writing. Here is a concrete example on how collaborative writing in the classroom can occur by using the book entitled English At Work 3 (Shearn, Ferris, and Tackett, 2016).

On the topic of "Communicating on the Phone: Meeting $(\mathrm{Re})$ arrangements", first of all lecturers give greetings to the students and say "How are you?" Then they were asked to introduce themselves to each other in order to become more familiar with each other. The lecturer told them to get information as much as possible for ten minutes before they were asked to form groups. Knowing each other is the most important thing before forming a group because they need mutual understanding in their group. Although the introduction only lasts for 10 minutes, it can help them to decide the formation of their group. A group formed should consist of four members, because in certain activities require activity in pairs, which make them easier in the group formation. Thus the exchange of seating positions and changes in the composition of the members can be efficiently implemented. Once they're comfortable with the composition of a group or in pairs, the lecturer can immediately begin the lesson.

The first activity is to have students work in pairs to write five kinds of reasons to make an appointment by phone. Working with a partner, make a list of five types of arrangement you would a make on the phone. Example: Dinner plans

After they finished writing five kinds of reasons, the students talked about the reasons in pairs to decide. They compare the answers in pairs. After that they discuss which reasons of the arrangement are difficult to fix, and which ones are easy. During this activity they may write and talk at the same time because sometimes they need ideas from others.

The next activity was listening to a short conversation that was played through loudspeakers connected to a portable computer. Students were asked 
to look at four pictures somewhere in the book, then they heard the 4 short conversations and match where each of the conversation was happening.

Once the answers were discussed, the conversation script was displayed and they were asked to read the script to compare between what they heard and what they read from it. The aim of this exercise is to make students sure about the contents of the conversation and notice how the sentences are pronounced.

The next exercise requires students to repeat the key words that appear when arranging an appointment. Lecturer played recordings containing words that are spoken, in which each word has a pause. This allows students enough time to imitate the spoken word:
1) cancel
2) delay
3) postpone
4) schedule
5) arrange
6) set up
7) rearrange
8) reschedule
9) put off
10) move back
11) conference call
12) appointment

Then the students work in pairs to complete the sentences with words that had been learned previously. As all students had finished completing the blanks, they were told to write four sentences in pairs. When finished, the results were compared with other pairs. When the answers were being compared, they exchanged their paper or books. While comparing the sentences, the students were allowed to mark with a pencil, criticize, give feedback and praise the results done by other pairs. To make grouping efficient, pairs that are supposed to make groups of four should sit close to each other. This can significantly reduce time to move around and minimize noise. 
The lecturer announced that the topic was making an appointment. Because in order to make an appointment people need scheduling that is related to future time, the lecturer introduces future tense sentence patterns along with examples. After being exposed with enough examples, the students complete a dialog according to the grammar rules taught by the lecturer. When they have finished, they compare the answer in pairs. The lecturer told them to analyze whether the reason is reasonable or not. After that, each student creates two or three sentences telling the reasons not to able to accept someone's invitation. As soon as they have finished, they exchange their work in pairs. Each of them should give comments and decides whether the invitations make sense or not.

Then they continued with reading activities. Each student was asked to read an article about the procedures for calling in the world of business or work environment. After that, each student was asked to answer questions about the passage. When the answer was completed, they compared the responses with their partner.

Around 30 minutes before each class ends, usually there is a writing activity. They have to write a paragraph containing 150 to 250 words. Students write in groups of four members (combination of two pairs sitting close to each other). They had to describe the effective ways to make someone feels confident while giving business presentation.

During the writing process, the classroom was noisy. The lecturer told them to speak English while discussing their writing. Even though they had to write using their own ideas, they were allowed to look at the article to see the sample. Each member participated and gave comments on what they had written. One of them read their writing loudly, while others were listening carefully before giving comments. They had to work together and avoid being dominant. Everybody contributed to accomplish the writing task. Instead of competing in the group, they proofread and revised the work. The checked and edited punctuation and grammar as well as the use of vocabulary. They made sure that before submitting their work, they did their best. 
Most of the students are basically happy with the collaborative writing strategy involving pairs and groups. But there are some who complain that they sometimes cannot rely on their friends. They say it is irritating when one member came late or was not active enough. However, in general they feel comfortable with the composition of pairs and groups, although there are still some who feel their skills do not help much to contribute to their team. The composition of pairs and groups determined by the students themselves make them feel comfortable. The pairs and groups can create friendship, so that the process of giving feedback, sharing information, or even criticizing others usually runs smoothly.

\section{CONCLUSION}

Writing is not merely expressing ideas and using writing techniques. To be able to write well, a student needs to be equipped with other skills. For example, by reading, students can analyze the structure of a paragraph. In addition, sufficient information from the reading can develop writing skill. Furthermore, writing activities should include interactions. Writing becomes more interesting if the activities are designed to create social interaction in the classroom. Through the group's collaboration in pairs and groups, students feel secure when their writing skill is too low. Nobody is dominant, so students who are more skillful will help, but those who are weak should try to contribute. Although the communication in pairs or groups often code switch between Indonesian and English, the spirit of collaboration makes writing less stressful. On the other hand, when writing practice is isolated, or without integration of other skills, students might feel that it is a hard task. 


\section{BIBLIOGRAPHY}

Akdemir, Elif. Ali Arslan. From Past to Present: Trend Analysis of Cooperative Learning Studies. International Conference on New Horizons in Education INTE 2012. Procedia-Social and Behavioral Sciences, 2013

Celik, Servet. Kubra Aytin, Esra Bayram. Implementing Cooperativ Learning in the Language Classroom Opinions of Turkish Teacher of English. Akdeniz LanguageStudies Conference 2012. (Procedia, social and Behavioral Sciences), 2013

Dang, Trang Thi Doan, Vietnamese EFL Students' Perceptions of Noticing-Based Collaborative Feedback on Their Writing Performance. Jurnal English Language Teaching; Canadian Center of Science and Education, Vol. 9, No. $5 ; 2016$

Fong, Lin Siew, Benefits of Collaborative Writing for ESL Advanced Diploma Students in the Production of Reports. Jurnal US-China Education Review, 2012

Harmer, Jeremy. How to Teach Writing, Essex: Pearson Education Limited, 2004

Johnson, D.W. \& Johnson, R.T. Leading Cooperative School (2nd ed). Edina, MN: Interaction Book Co., 1994

Masoud Aziznezhad,Masoud Hashemi, Sohrab Darvishi. Application of Cooperatif Learning in EFL classes to enchance the students Language Learning. 3rd World Conference on Learning, Teaching and Educational Leardership (WCLTA-2012). Journal Science Direct. Procedia Soscial and Behavioral Sciences.

Zhou, Hui. Enhancing Non-English Major's EFL Motivation through Cooperative Learning. 2011 International Conference on Enviromental Science and Engineering (ICESE 2011). Procedia Enviromental Science 12, 2012 